\title{
Task force to review services for drug misusers
}

\author{
Duncan Raistrick
}

In the past ten years there has been enormous growth in the size and the range of services for people who misuse illicit drugs. The blueprint for service development was a report from the Advisory Council on the Misuse of Drugs entitled Treatment and Rehabilitation (Department of Health and Social Security, 1982). In response, growth of the non-statutory sector was particularly encouraged and the whole venture was funded through a series of Department of Health initiatives aimed at both the prevention of the spread of HIV infection and the treatment of drug dependence. The time was right in the mid1980 s for the renaissance of harm reduction. The government was willing to accept any measures to prevent an AIDS epidemic, nonstatutory agencies were in the ascendancy, and the field lacked any convincing view on treatment effectiveness. Guidance from the Advisory Council on the Misuse of Drugs (Department of Health and Social Security, 1988; Department of Health, 1993), however, was careful not to endorse wholesale adoption of a harm reduction approach, but rather to see, for example, needle and syringe exchange schemes and substitute prescribing as useful elements of a public health strategy which both contained the spread of HIV and initiated the process of becoming drug free.

The Department of Health has run an effective HIV control programme but, as perceptions of risk from HIV have diminished, new concerns have come onto the drugs agenda for the late 1990s. Fear of an AIDS epidemic has been replaced by fears of criminal activity, and the pendulum has again swung against too liberal an interpretation of harm reduction. Prescribing drugs for drug misusers has always been contentious and expensive; therefore, a reversal of the harm reduction policy was expected when, in 1994, Ministers set up a task force to review the effectiveness of services "... . in relation to the principal objective of assisting drug users to achieve and maintain a drug free state . . ." (Department of Health, 1996a). The task force consisted of 11 members.

Tackling Drugs Together (Department of Health, 1995) committed the Department of Health to produce purchasing guidance for
1997-1998, based on the task force review. Tackling Drugs Together identified a reduction in the acceptability and availability of drugs to young people, an increase in the safety of communities from drug-related crime, and a reduction in the health risks and other damage related to drug misuse as key elements of government strategy. In response, the task force set out to map and categorise existing services, and to conduct a multi-centre study of treatment processes and outcomes, referred to as NTORS (National Treatment Outcome Study). NTORS is a prospective, uncontrolled trial which has recruited 1110 subjects. The central finding from NTORS so far is that "treatment works" in terms of reducing drug involvement, improving health, reducing criminal activity, and improving psychological well-being. All four treatment modalities investigated (in-patient, residential rehabilitation, methadone maintenance and methadone reduction) have shown benefit, maintained at six-month follow-up. It is of interest for mental health workers that the percentage of people reporting feeling hopeless about the future fell from 63 to $44 \%$ and those expressing suicidal thoughts from 29 to $16 \%$. The follow-up will continue for five years.

The task force is imprecise in categorising methadone programmes and is content that any prescribing programme delivers both social and health benefits. However, Raistrick (1997) has argued that the specific purposes of substitute prescribing must be understood by both purchasers and providers. These purposes, most simply characterised as social control, individual treatment of dependence and protection of the public health, have implications for the source of finance, case management and service delivery systems. The Amsterdam model (Plomp et al, 1996) has successfully operationalised roles for general psychiatrists, general practitioners and psychiatrists specialising in substance misuse, and recognises that doctors are used to caring for individuals rather than acting as agents of social policy. Clarity of purpose should form the basis of substitute prescribing.

Surprisingly the task force rather neglects the role of the general psychiatrist. This is 
unfortunate in that substance misuse problems are commonplace in the general psychiatry clinic. The Home Office notification system, a reliable indicator of trends in numbers of drug misusers seen by doctors, showed an increase in new notifications of heroin users from 6328 in 1991 to 11620 in 1995: notification of cocaine users increased from 882 to 1809 in the same period (Home Office, 1996). The Home Office Index was discontinued in May 1997: data are now available from regional databases which collect from a wider range of sources than medical practitioners. Without the Home Office Index there is an argument for establishing a new system to monitor and control prescribing. Points of interest from the regional databases are an increase in the reporting of so-called 'dance drugs', which are commonly the drugs associated with mental illness problems, and second, very few returns made by general psychiatrists (Department of Health, 1996b). At an anecdotal level specialist services seem to have dealt with increased demand from opiate users by displacing people who misuse alcohol into the care of general practitioners and general psychiatrists, leaving problems of drug related mental illness falling between addiction services, Accident and Emergency departments, liaison, forensic, child and adolescent, and general psychiatry. In a weak recommendation on meeting the needs of people with coexisting drug and mental illness problems, the task force said only that "Purchasers and providers should ensure that people working in both drugs and mental illness services are aware of the need to identify and respond to problems of combined psychiatric illness and drug misuse".

The task force review ducks some rather crucial issues: (a) there is no underpinning theoretical basis to the task force thinking and therefore inconsistencies and contradictions arise; (b) there is a failure to address the meaning of counselling, having concluded that unstructured counselling is ineffective but common in the UK it is recommended that ". . . counselling should be recognised as a core component of drug treatment..."; (c) there is a failure to define the meaning of 'shared care' and to state whether or not general practitioners must include substitute prescribing as part of contracted general medical services; and there is a failure to identify the resources required to implement the 79 recommendations.

It is not unusual to find quangos made up of people who are unfamiliar with their committee's area of work and so it was with the Drug Misuse Task Force. On the one hand, bodies such as the Royal College of Psychiatrists are aghast at the lack of expert input, on the other hand professionals may benefit from a quango which is seen to be independent of any vested interests and whose findings politicians will therefore accept. Overall, specialists have welcomed the task force review, which was able to secure support for the continuation of methadone programmes. None the less specialist doctors will want to reinforce the idea of controlled, structured substitute prescribing as good practice (Sorenson, 1996) and necessary to prevent young deaths (Cairns $e t$ al. 1996). As for non-specialists, Brabbins \& Poole (1996) have suggested the need for a more cohesive response to drug induced psychosis. Starting from this point of common clinical interest psychiatrists might all benefit from conducting a substance misuse needs analysis for their whole service, with a view to informing local drug action teams of the scale and significance of mental illness coexisting with drug dependence. The role of specialists, general practitioners and general psychiatrists is being reviewed by a Department of Health Working Group: new guidelines are expected in the Autumn.

\section{References}

Brabiins, C. \& POOLE, R. (1996) Psychiatrists' knowledge of drug induced psychosis, Psychiatric Bulletin, 20, 410 412.

Cairns, A. Roberts, I. S. D. \& Benbow, E. W. (1996) Characteristics of fatal methadone overdose in Manchester, 1985-94. British Medical Joumal, 313. 264-265.

Department of Health (1993) AIDS and Drug Misuse Update: Report by the Advisory Council on the Misuse of Drugs, pp. 42-44 London: HMSO.

- (1995) Tackling Drugs Together: A Strategy for England 1995-1998. London: HMSO.

- (1996a) The Task Force to Review Services for Drug Misusers: Report of an Independent Review of Drug Treatment Service in England. London: HMSO.

- (1996b) Statistical Bulletin. London: Government Statistical Service.

DEPARTMENT OF HEALTH AND SOCIAL SECURTY (1982) Treatment and Rehabilitation: Report of the Advisory Council on the Misuse of Drugs. London: HMSO.

- (1988) AIDS and Drug Misuse Part 1: Report by the Advisory Council on the Misuse of Drugs, pp.47-49. London: HMSO.

HOME OFFICE (1996) Statistical Bulletin, 15. London: Government Statistical Service.

PLOMP, H. N., VAN DER HEK, H. \& ADER, H. J. (1996) The Amsterdam Methadone Dispensing Circuit: genesis and effectiveness of a public health model for local drug policy. Addiction, 91, 711-721.

RAISTRICK, D. (1997) Substitute prescribing. Social policy or individual treatment? Druglink, March/Aprll, 16-17.

SORENSEN, J. L. (1996) Methadone treatment for opiate addicts: When properly regulated. still a valuable outpatient treatment. British Medical Joumal, 313. 245-246.

Duncan Raistrick, Clinical Director, Leeds Addiction Unit, 19 Springfield Mount, Leeds LS2 9NG 